Eos, Vol. 76, No. 42, October 17, 1995
E O S
T R A N S A C T I O N S,
A M E R I C A N
G E O P H Y S I C A L
U N I O N

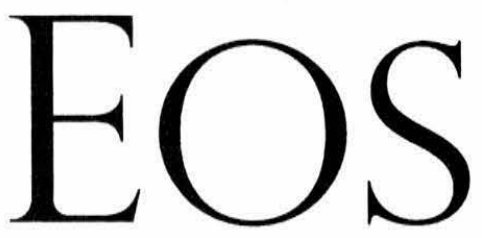

VOLUME 76 NUMBER 42

OCTOBER 17, 1995

PAGES 417-428

\title{
Anticipating the Successor to Mexico's Largest Historical Earthquake
}

PAGES 417, 424

C. DeMets, I. Carmichael, T. Melbourne, O. Sanchez, J. Stock, G. Suarez, and K. Hudnut

Note in proof: On October 9, as this article was being prepared for publication, a magnitude 7.6 earthquake occurred beneath the Jalisco region and caused significant loss of life and property. This earthquake highlights the societal need for accurate measurements of crustal strain rates in earthquake-prone zones. In the coming months, we plan to measure the amount of displacement that occurred within the GPS network during and after this earthquake.

On June 3, 1932, the largest earthquake recorded in Mexico this century rocked the state of Jalisco, causing widespread casualties and damage. This $\mathrm{M}=8.2$ earthquake and a magnitude 7.8 aftershock ruptured +: Rivera subduction zone (Figure 1), which accommodates downward thrusting of the Rivera plate beneath the Jalisco region [Eissler and McNally, 1984; Singh et al., 1985]. Since 1932, the Rivera subduction zone has been relatively aseismic. This indicates that the subduction fault is either locked and accumulating strain, or slipping freely. If the subduction fault is locked, a likely possibility, stored strain equal to the amount released by the 1932 earthquakes could reaccumulate in as little as 80 years at the average Rivera-North America convergence rate of 3

Charles DeMets, of Geology and Geophysics, University of Wisconsin, 1215 W. Dayton St., Madison, WI 53706; Ian Carmichael, Department of Geology and Geophysics, University of California, Berkely, CA 94720; Osvaldo Sanchez and Gerardo Suarez, UNAM/Instituto de Geofisica, Postal 21-499, Mexico City, D.F. 04510 Mexico; Tim Melbourne and

Joann Stock, Seismological Laboratory 252-21, California Institute of Technology, Pasadena, CA 91125; Ken Hudnut, U. S. Geological Survey, 521 S. Wilson Ave., Pasadena, CA 91106 m.y. [DeMets and Stein, 1990]. It could accumulate sooner if the convergence rate has increased significantly since 3 m.y. [Bandy and Pardo, 1994]

In March 1995, a long-term project was begun to monitor subduction-related strain accumulation and investigate rift-related deformation above the subducting Rivera and Cocos plates. Initial measurements of baseline lengths and orientations of 15 sites in western Mexico (Figure 1) were made using Global Positioning System satellite receivers.

The Jalisco region is an attractive setting for a GPS experiment. It offers a rare opportunity to observe how a continent deforms above two subducting slabs. The Cocos plate subducts approximately 1.5-2 times faster than the Rivera plate, which suggests that the Rivera-Cocos boundary should accommodate significant relative motion underneath the continent. How differential motion between the downgoing slabs affects deformation of the overlying continent is unclear. However, subduction is known to affect onshore neotectonics profoundly.

Two active rift systems bound a less faulted, topographically high, and rugged Jalisco "block" that overlies the Rivera plate. They are the north trending Colima graben, which may lie above the subducted RiveraCocos boundary, and the northwest trending Tepic-Zacoalco rift zone, which extends northwest to the Gulf of California. These rift systems intersect a third southeast trending zone of active faulting, the Chapala rift, and form a continental triple junction near Guadalajara, Mexico's second largest city.

The two plates subducting beneath Jalisco also affect the volcanism of the overlying Jalisco block. The Jalisco region is a volcanologist's playground, containing what may be the world's most diverse volcanic rocks. Much of the volcanism is focused in grabens that indicate active regional extension. The Tepic-Zacoalco fault zone and Colima graben, which separates the Jalisco block from the North American plate, contain both active and dormant andesitic volcanos, including Volcan Colima, North America's most active volcano. The Chapala-Tula fault zone, part of the TransMexican Volcanic Belt, also contains many active volcanos. Additional young volcanism is also concentrated in several smaller grabens, which form a volcanic front approximately $90 \mathrm{~km}$ from the trench. Preliminary images of the Benioff zone suggest that the Rivera slab dips about $45^{\circ}$, reaching depths of $100 \mathrm{~km}$ beneath the volcanic front defined by the small grabens near the trench [Pardo and Suarez, 1995].

Speculation about a link between the subducting Rivera and Cocos plates and the onshore volcano-tectonic record of the Jalisco region have led to several classes of models for the deformation in the region. In one model the Colima graben represents deformation of the continent above a tear in the subducting slab [Nixon, 1982]. Others consider the Colima graben to be an early manifestation of an eastward jump of the East Pacific Rise [e.g., Luhr et al., 1985]. Other models invoke differential motion and oblique subduction of the Rivera and Cocos plates beneath the continental margin to explain extension along the Colima graben and other fault zones [DeMets and Stein, 1990;

Bandy et al., 1995]. One model attributes the volcanism and rifting at the Colima graben to a hotspot beneath the Guadalajara region [Moore et al., 1994]. GPS measurements are best suited for distinguishing between models that invoke differential motion and oblique subduction of the Rivera and Cocos plates. These models postulate that the dip, configuration, convergence rate, and angle of obliquity of the downgoing slabs are important in controlling deformation and volcanism within the overlying plate. In particular, GPS measurements will be used to test the predictions of two alternative models for present-day Rivera and Cocos plate motion beneath the continental margin. One model uses magnetic anomalies from the $\mathrm{Pa}$ cific-Rivera rise in conjunction with plate circuit closures to predict differential motion 
Eos, Vol. 76, No. 42, October 17, 1995

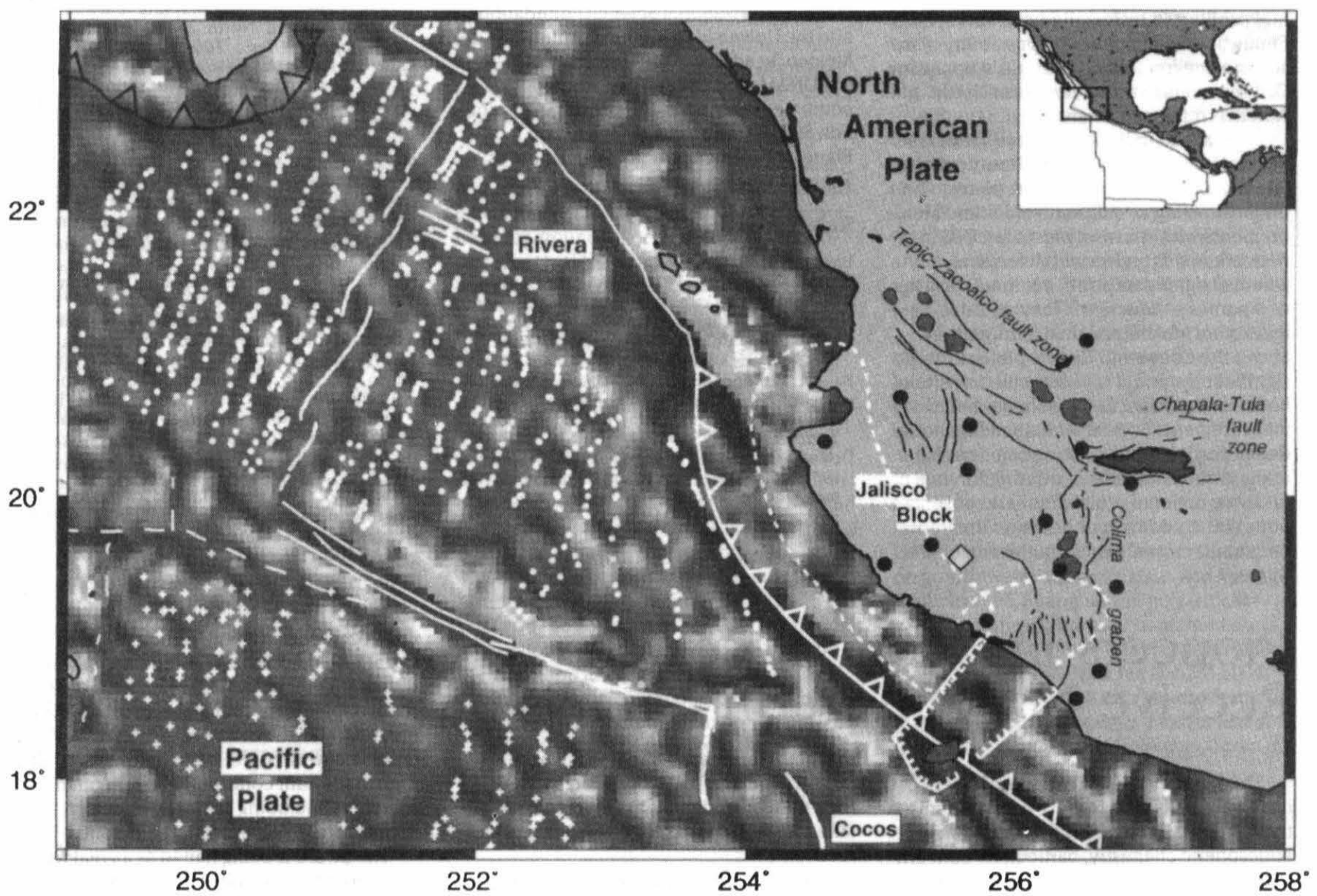

Fig. 1. Neotectonic features in the Jalisco block and Rivera plate region. Solid circles represent GPS sites occupied in 1995 . The yellow diamond shows estimated location of the June 3, 1932, earthquake [Eissler and McNally, 1982], and the white short dashed lines show the estimated extent of aftershocks for the June 3, 1932, earthquake and the zone where the June 18, 1932, aftershock caused the most damage [Singh et al., 1985]. Red regions indicate volcanic centers active in the last few thousand years. The green-shaded area onshore is Lake Chapala. The offshore region shows the vertical gravity gradient illuminated from the southwest (gravity field supplied courtesy of Dave Sandwell). Solid white lines show active plate boundaries and dashed white lines show inactive plate boundaries. The white dots and crosses show magnetic anomaly crossings being used by S. Traylen and C. DeMets to model the post-10 Ma kinematic evolution of the Rivera plate. Original color image appears at the back of this volume.

of $15 \pm 5 \mathrm{~mm} / \mathrm{yr}$ between the subducting Rivera and Cocos plates [DeMets and Stein, 1990]. An alternative model predicts that motion between the Rivera and Cocos plates must be slow or nonexistent because there is no clear boundary west of the Middle America trench and because of the seismic characteristics of the two subducting plates [Kostoglodov and Bandy, 1995].

These models predict different patterns of large-scale strain accumulation within the overlying North American plate. According to the former model, strain should accumulate significantly faster over the subducting Cocos plate than over the Rivera plate, with a discontinuity somewhere in the vicinity of the Colima graben. According to the latter model, strain rates within the North American plate should decrease to the northwest, with no discontinuity nearthe Colimagraben.

The regional strain field is likely to be dominated by subduction-related strain, with a smaller contribution from rift-related fault slip and block rotation. GPS measurements, when combined with seismological and volcanological constraints on the dip and configuration of the Benioff zone, should lead to a suite of plausible models that link the onshore deformation to the motions of the slabs. In the short-term, the along-trench variations in the strain rates and maximum shortening directions will be used to find the transition between lithosphere overlying the subducting Rivera and Cocos plates, and to determine whether this transition coincides with the Colima graben and/or with a gravity anomaly attributed to the subducted portion of the Rivera-Cocos boundary [Bandy et al., 1995]. More challenging objectives include measuring vertical uplift rates and extracting information on rift-related deformation from the subduction-related strain.

Next year progress will be made on three fronts. Suarez and Sanchez plan to install a passive seismic array in the Jalisco region to image the Benioff zone and other faults that generate microseisms. In addition, GPS meas- 
urements at several sites in the existing network will be repeated, and closely spaced geodetic monuments along a trench-normal profile will be installed and surveyed. Finally, we will explore the possibility of installing one or more continuously operating GPS receivers to establish a mini-North America reference frame.

The Jalisco region of western Mexico is an excellent site for studying how continental lithosphere responds to two plates underthrusting at different velocities. Measurements within a newly installed GPS network in this region will determine whether significant strain accumulation accompanies subduction. They will also determine whether strain accumulation above the Cocos and Rivera plates differs significantly, and if so, where the transition between the strain fields is located. GPS measurements over several decades should detect vertical uplift and motion across the many grabens of Jalisco, offering for the first time regional-scale kinematic observations that could help understand the enigmatic volcanic rocks in this region.

\section{Acknowledgments}

Seed funding for this project was provided by the National Science Foundation and the Universidad Nacional Autonoma de Mexico. In addition, the University of Wisconsin, UNAM, and Caltech contributed equipment to support this project. Contribution 5607, Division of Geological and Planetary Sciences, California Institute of Technology.

\section{References}

Bandy, W., C. Mortera-Gutierrez, J. Urrutia-Fucugauchi, and T. W. C. Hilde, The subducted Rivera-Cocos plate boundary: Where is it, what is it, and what is its relationship to the Colima rift?, Geophys. Res. Lett., in press, 1995.

Bandy, W., and M. Pardo, Statistical examination of the existence and relative motion of the Jalisco and southern Mexico blocks, Tectonics, 13, 755, 1994

DeMets, C., and S. Stein, Present-day kinematics of the Rivera plate and implications for tectonics of southwestern Mexico, J. Geophys. Res., 95, 21,931, 1990

Eissler, H. K., and K. C. McNally, Seismicity and tectonics of the Rivera plate and im- plications for the 1932 Jalisco, Mexico, earth quake, J. Geophys. Res., 89, 4520, 1984.

Kostoglodov, V., and W. Bandy, Seismotec tonic constraints on the rate between the Rivera and North American plates, J. Geophys. Res., 100, 17,977, 1995.

Luhr, J. F., S. A. Nelson, J. F. Allan, and I. S. E. Carmichael, Active rifting in southwestern Mexico: Manifestations of an incipient eastward spreading-ridge jump, Geology, 13, 54, 1985.

Moore, G., C. Marone, I. S. E. Carmichael, and $\mathrm{P}$. Renne, Basaltic volcanism and extension near the intersection of the $\mathrm{Si}$ erra Madre volcanic province and the Mexican volcanic belt, Geol. Soc. Am Bull., 106, 383, 1994.

Nixon, G. T., The relationship between Quaternary volcanism in central Mexico and the seismicity and structure of subducted oceanic lithosphere, Geol. Soc. Am. Bull., 93, 514, 1982.

Pardo, M., and G. Suarez, Shape of the subducted Rivera and Cocos plates in southern Mexico: Seismic and tectonic implications, J. Geophys. Res., 100, $12,357,1995$.

Singh, S. K., I. Ponce, and S. P Nishenko, The great Jalisco, Mexico, earthquakes of 1932: Subduction of the Rivera plate, Bull. Seismol. Soc. Am., $75,1301,1985$

\section{Pioneers in Ozone Research Receive Nobel Prize in Chemistry}

\section{PAGES $417-418$}

The Royal Swedish Academy of Sciences has awarded its 1995 Nobel Prize in chemistry to three AGU members for their work in atmospheric chemistry, particularly concerning the formation and decomposition of ozone. Only one other Nobel prize has ever been awarded in the realm of atmospheric research. The honorees are professors Paul Crutzen of the Max-Planck Institute for Chemistry in Mainz, Germany; Mario Molina of the Massachusetts Institute of Technology; and F. Sherwood Rowland of the University of California, Irvine. The Academy credits the three with contributing to "our salvation from a global environmental problem that could have catastrophic consequences."

Crutzen, Molina, and Rowland are noted for their pioneering contributions to explaining how ozone forms and decomposes through chemical processes in the atmosphere. They have shown how sensitive the ozone layer is to the influence of anthropogenic emissions of certain compounds. The thin ozone layer has proven to be an "Achilles heel" that may be seriously damaged by moderate changes in the composition of the atmosphere. The work of these pioneers contributed in 1987 to the signing of the Montreal Protocol, a multinational accord that severely limited CFC emissions to protect the ozone layer. With a few exceptions, the gases that pose the greatest threat to the ozone layer will be completely banned by 1996 . If the protocol guidelines are followed, it will take at least 100 years for the ozone layer to recover.

In 1930, English physicist Sidney Chapman developed the first photochemical theory for the formation and decomposition of ozone in the atmosphere. In 1970, Crutzen took the first fundamental step toward a deeper understanding of the chemistry of the ozone layer. He showed that the nitrogen oxides $\mathrm{NO}$ and $\mathrm{NO}_{2}$ react - without being consumed-with ozone, thus accelerating the rate of reduction of the ozone content. His work also contributed to the rapid development of research on global

biogeochemical cycles.

The next leap in knowledge of ozone chemistry was taken in 1974, when Molina and Rowland published their widely noted Nature article on the threat to the ozone layer from chlorofluorocarbon (CFC) gases known as "freons." These gases were being used in spray bottles, as the cooling medium in refrigerators and air conditioners, and in plastic foams. The two scientists realized that CFCs, which are chemically stable, could gradually be transported through normal air circulations to the stratosphere. There, intense ultraviolet light could break up the molecules, releasing chlorine, which cata- lyzes ozone destruction. Although controversial at first, the Molina-Rowland hypothesis was strengthened in 1985 when a drastic seasonal depletion of stratospheric ozone over the Antarctic, the ozone hole, was discovered. The work of Molina and Rowland built upon important contributions from other researchers, including James Lovelock, Richard Stolarski, and Ralph Cicerone.

The award is being hailed as a great recognition for atmospheric science as a whole. National Center for Atmospheric Research atmospheric chemist Jack Calvert, who worked with all three Nobel recipients, said, "I was impressed that they not only discovered the ozone threat, but were willing to go to the government and say, "We need to do something about this.' They are really heroes to us."

Crutzen, Molina, and Rowland are members of AGU,Crutzen and Rowland being AGU Fellows. Crutzen received his doctorate in meteorology from Stockholm University in 1973. He is a member of the Royal Swedish Academy of Sciences, the Royal Swedish Academy of Engineering Sciences, and Academia Europaea. Molina received his doctorate in physical chemistry from the University of California, Berkeley. He is a member of the U.S. National Academy of Sciences. Rowland received his doctorate in chemistry from the University of Chicago. He is a member of the American Academy of Arts and Sciences and the U.S. National Academy of Sciences, where he is currently foreign secretary. He was awarded AGU's Roger Revelle Medal in 1994. 